\title{
Chemical Compositions of African Trade Bracelets (Manillas) via Energy Dispersive X-Ray Fluorescence
}

\author{
Mike Kuntz, Jennifer Ferguson, Vincent Iduma, \\ Renee Kuzava, and Mark Benvenuto \\ Department of Chemistry and Biochemistry \\ University of Detroit Mercy \\ 4001 W. McNichols Road \\ Detroit, Michigan 48219-0900 USA
}

Received March 4, 2002 Accepted March 13, 2002

\begin{abstract}
Sixteen small, west African trade bracelets called manillas, and one large, African trade bracelet referred to as a king manilla based on its size, were analyzed via energy dispersive x-ray fluorescence spectrometry and compared for the following elements: copper, zinc, tin, lead, antimony, and arsenic. The composition of the bracelets varied widely in the amount of lead present, especially when compared to the official amounts of lead allowed by the various manufacturing concerns. The king manilla showed a markedly different chemistry than the sixteen smaller manillas, consistent with the belief such large manillas were not manufactured in the same location as the small.
\end{abstract}

\section{INTRODUCTION}

Copper objects have been traded as items of money and wealth in sub-Saharan Africa for hundreds of years [1]. European trading companies produced millions of copper bracelets, known as manillas, for use in west African trade; and their use continued in many areas well into the twentieth century [1]. While these items have been of interest to and have been studied by numismatists who specialize in non-traditional forms of money, they seem not to have been studied in terms of their metallurgical composition, perhaps because early, published reports simply have stated what their compositions should be [1-3]. Until this time, there appears to have been no attempt to determine the chemical make up of any sampling of these bracelets via a non-destructive, analytical chemical technique.

The sixteen smaller bracelets analyzed here vary in size, as shown in photographs 1 - 16. In addition, there are certain differences in style, as can be seen most obviously when comparing photograph 16 to the others. The king manilla is considerably larger, as seen in photograph 17 , being approximately 12" long. The bracelets have been matched to their type in the Opitz reference [1], and are listed in Table 1. Where possible, their presumed city, country, or region of manufacture, as well as possible dates of manufacture, are also listed.

\section{PROCEDURE}

Bracelets 1 - 10 were purchased for study, and bracelets $11-17$ were provided as loans from the American Numismatic Association, headquartered in Colorado Springs, Colorado. Bracelets $1-10$ were wiped with a Kimwipe prior to exposure to Xrays, while bracelets $11-17$ were not cleaned in any way prior to exposure. [See the Appendix for photographs of the manillas.] 


\begin{tabular}{|c|c|c|c|}
\hline $\begin{array}{c}\text { Sample } \\
\text { Number }\end{array}$ & Opitz Type & $\begin{array}{c}\text { City/County/Region of } \\
\text { Production }\end{array}$ & Date \\
\hline 1 & atoni & Birmingham, England & \\
\hline 2 & atoni & Birmingham, England & \\
\hline 3 & onoudu & Birmingham, England & 1856 \\
\hline 4 & onoudu & Birmingham, England & 1856 \\
\hline 5 & onoudu & Birmingham, England & 1856 \\
\hline 6 & onoudu & Birmingham, England & 1856 \\
\hline 7 & onoudu & Birmingham, England & 1856 \\
\hline 8 & onoudu & Birmingham, England & 1856 \\
\hline 9 & onoudu & Birmingham, England & 1856 \\
\hline 10 & popo & French & \\
\hline 11 & atoni & Birmingham, England & \\
\hline 12 & atoni & Birmingham, England & \\
\hline 13 & atoni & Birmingham, England & \\
\hline 14 & atoni & Birmingham, England & \\
\hline 15 & bidda & & \\
\hline 16 & popo & French & \\
\hline 17 & king & Africa & \\
\hline
\end{tabular}

Table 1. The manillas tested: their type, point of production, and date of production.

Beyond this, each bracelet was examined to ensure that the points of exposure to the $X$ ray beam were clean and free from patination. The bracelets all have a torque shape with flared ends. The X-ray beam was directed at three equally spaced points on each side of each bracelet, for a total of six points per sample. These were then averaged for each elemental percentage. The samples were examined via energy dispersive X-ray fluorescence on a Kevex
Spectrace Quanx spectrometer with Si (Li) detector for the following elements: $\mathrm{Cu}, \mathrm{Zn}$, $\mathrm{Sn}, \mathrm{Pb}, \mathrm{Fe}, \mathrm{Ni}, \mathrm{Mn}, \mathrm{Sb}, \mathrm{Au}, \mathrm{Pt}, \mathrm{Pd}$, and $\mathrm{Ag}$. Excitation conditions for each sample were as follows: $20 \mathrm{kV}, 0.10 \mathrm{~mA}, 100$ second count, $\mathrm{K}$. for $\mathrm{Fe}, \mathrm{Co}, \mathrm{Ni}, \mathrm{Cu}, \mathrm{Zn}, \mathrm{As}, \mathrm{Pt}$, $\mathrm{Au}, \mathrm{Bi}$, and $\mathrm{Pb}$, followed by $45 \mathrm{kV}, 0.72 \mathrm{~mA}$, 60 second count, $L$ lines, for $P d, A g, S n$, and $\mathrm{Sb}$, using a rhodium target $\mathrm{X}$-ray tube. Pure element standards and fundamental software were utilized in determining

Figure 1: Percent Composition of Copper

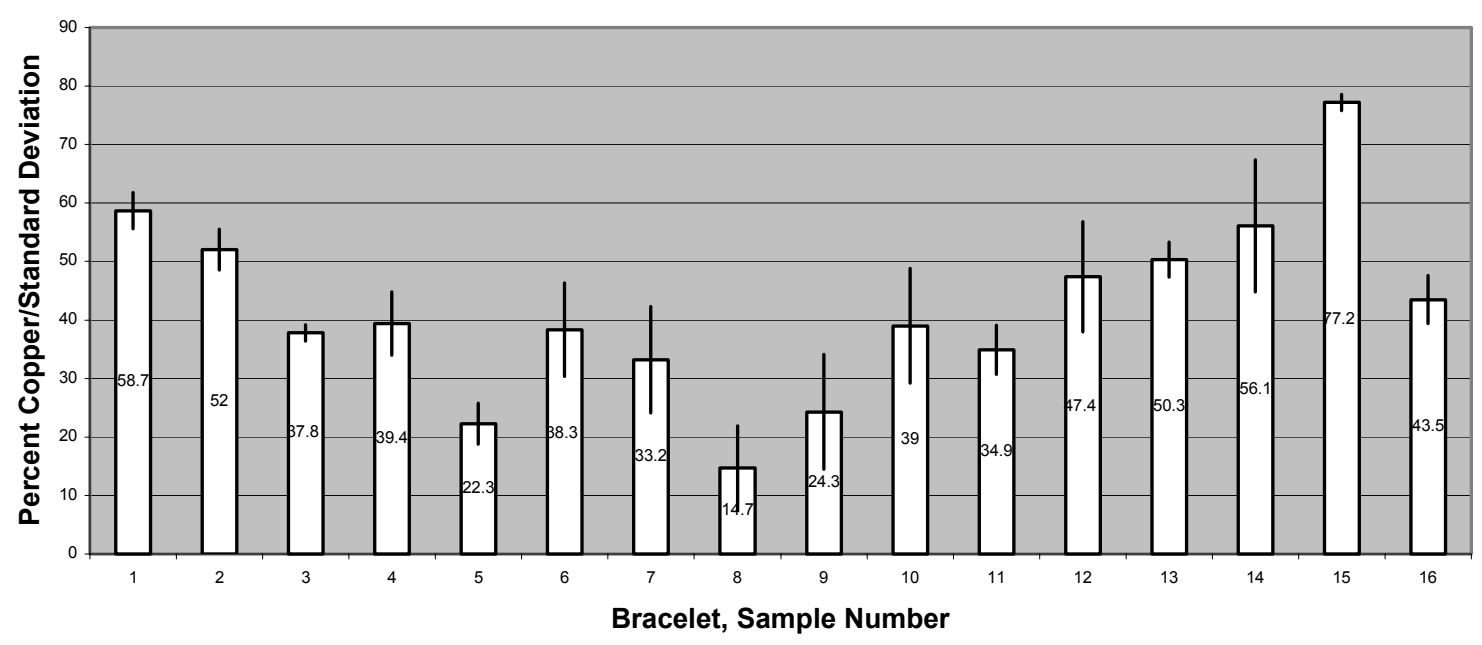


all elemental concentrations. Brass standard sample disks of known concentrations were run before the samples each day and after each day's samples. Concentrations (in percent) of the major components of the standards were:

\begin{tabular}{|l|l|l|}
\hline Element & Standard 1 & Standard 2 \\
\hline $\mathrm{Cu}$ & $80.3 \%$ & $77.8 \%$ \\
\hline $\mathrm{Zn}$ & 2.5 & 3.7 \\
\hline $\mathrm{Pb}$ & 2.0 & 6.5 \\
\hline $\mathrm{Sn}$ & 14.1 & 10.5 \\
\hline
\end{tabular}

Figure 2: Percent Composition of Lead

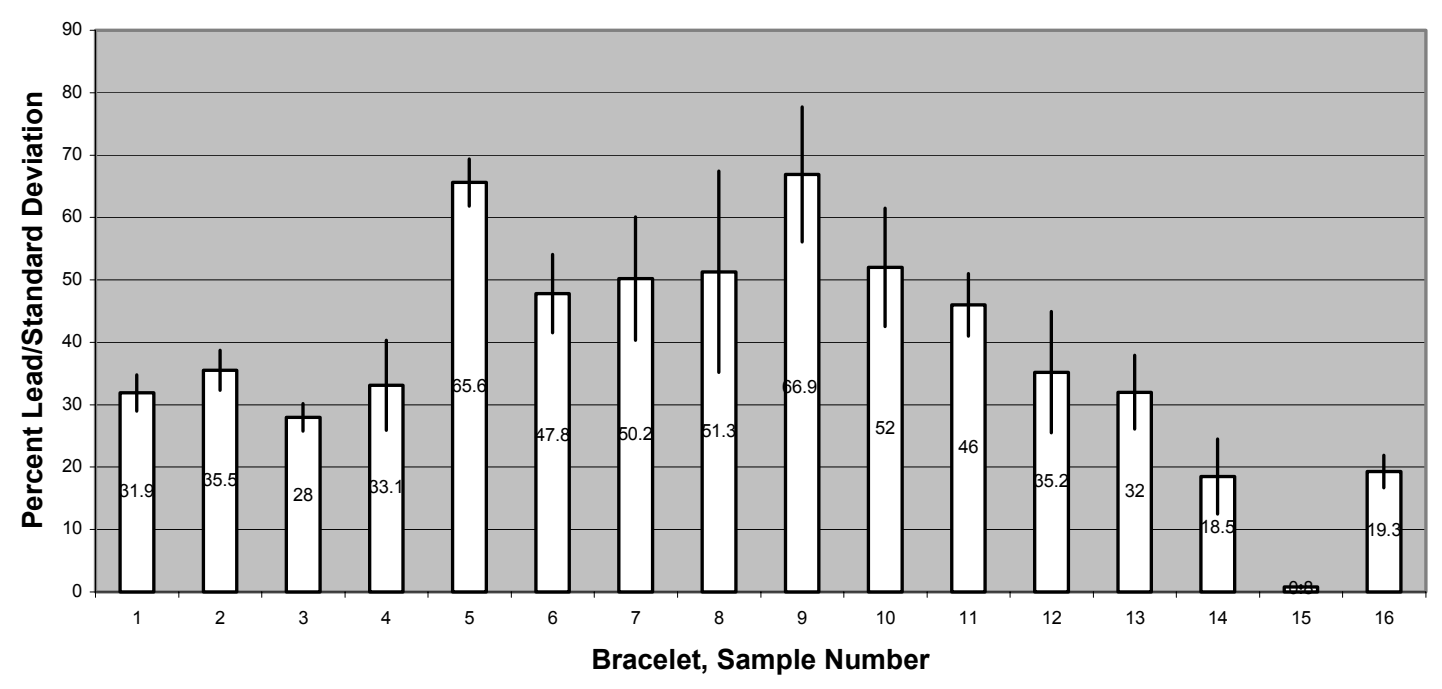

Figure 3: Percent Composition of Zinc

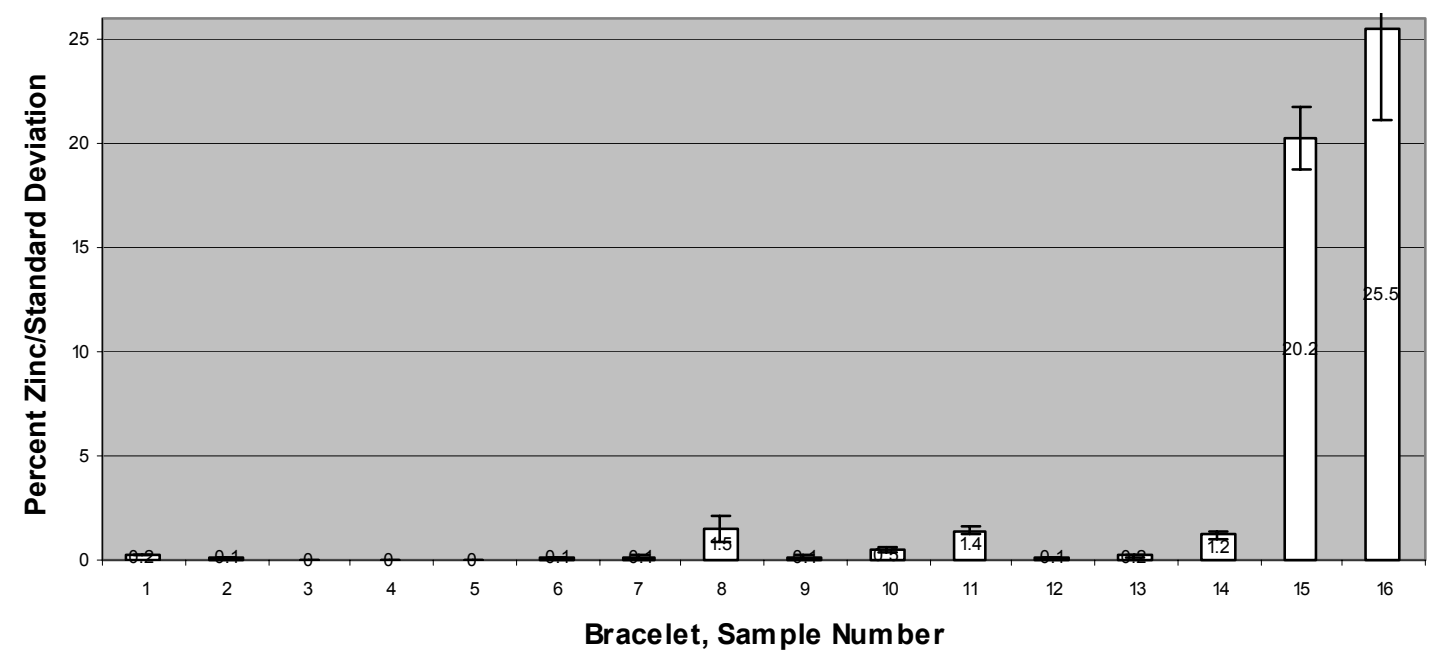

III. ELEMENTAL COMPOSITIONS, THE SMALL MANILLAS

The compositions of the major components of bracelets 1-16 are illustrated graphically in Figures $1-6$. It was surprising to note that copper was not present to the amount of even $50 \%$ in eleven of the sixteen samples, as seen in Figure 1. In addition, it was quite unexpected to see the lead percentages rise as high as they did - over $40 \%$ in seven of the samples, and over $50 \%$ in five of those 
seven - as shown in Figure 2. Since prior reports indicate the bracelets should be copper with no more than $25 \%$ lead [4], Figures 1 and 2 should add up to total percentages at or close to $100 \%$ (allowing for impurities that were not refined away).
This appears never to be the case, which indicates other elements are present in significant amounts in the alloys of each sample, and which is also consistent with similar findings in African copper-based artifacts [5].

Figure 4: Percent Compoistion of Tin

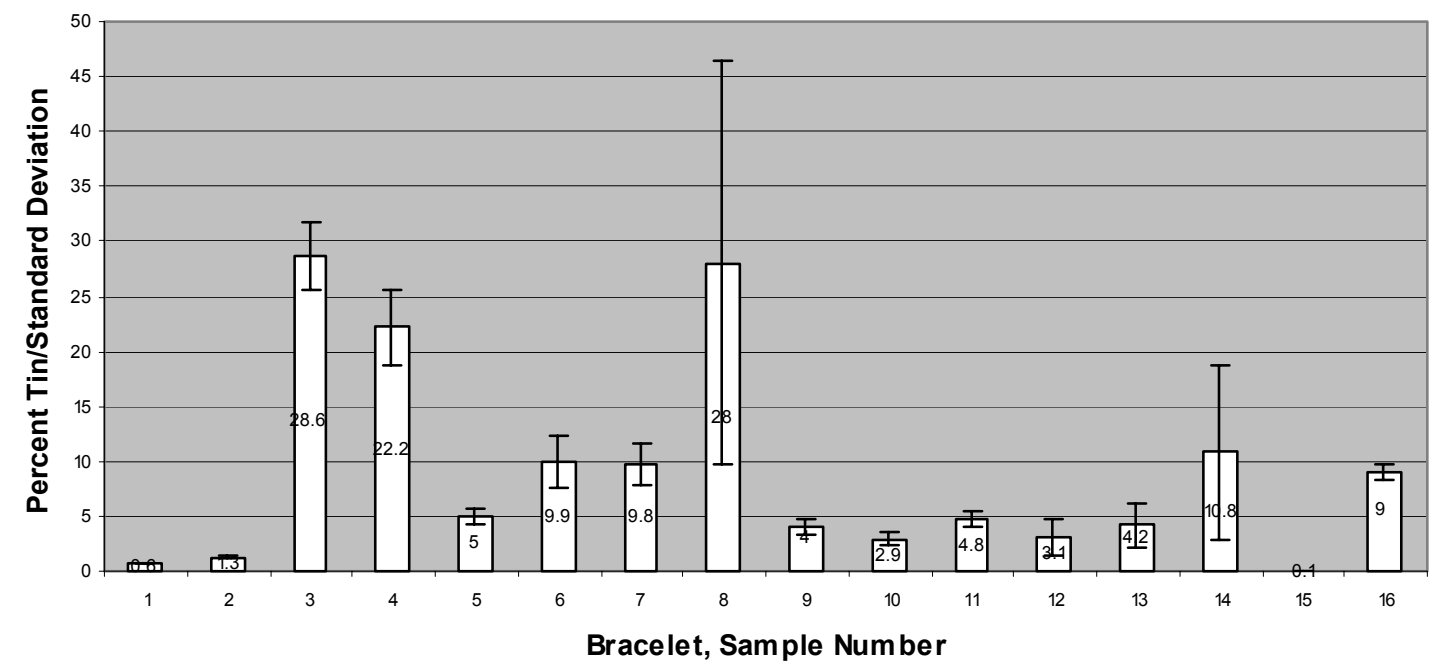

Figure 5: Percent Composition of Antimony

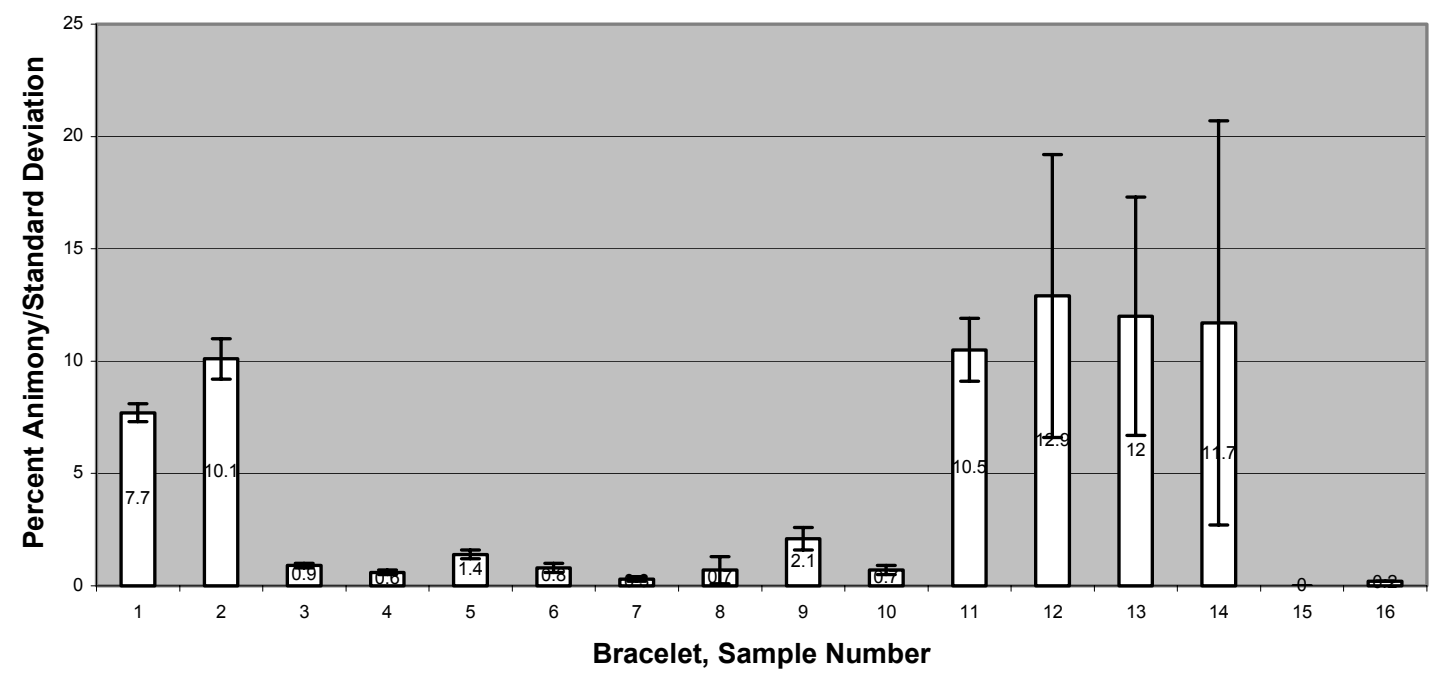

Figure 3 graphs zinc percentages, and shows that only bracelets 15 and 16 have a large percentage of zinc. In bracelets $1-14$, zinc appears to be present as no more than a trace element, though the pure element standards and brass standards used as known concentrations make such trace numbers for zinc and other 
elements semi-quantitative. This does however indicate that these fourteen samples cannot be accurately called leaded brass, though 15 and 16 can be. On a related note, the presence of a significant amount of tin (graphed in Figure 4) would indicate the bracelets to be leaded bronze; and it does appear that tin is present in greater amounts than zinc in all but three of the bracelets. Both zinc and tin concentrations are lower than lead though, in all but bracelets 15 and 16 . As well, the standard deviations for lead and tin do become large in some of the samples. This may be a result of long-term storage of those samples in a chemically active environment, such as being buried in acidic soil.

\section{Figure 6: Percent Composition of Arsenic}

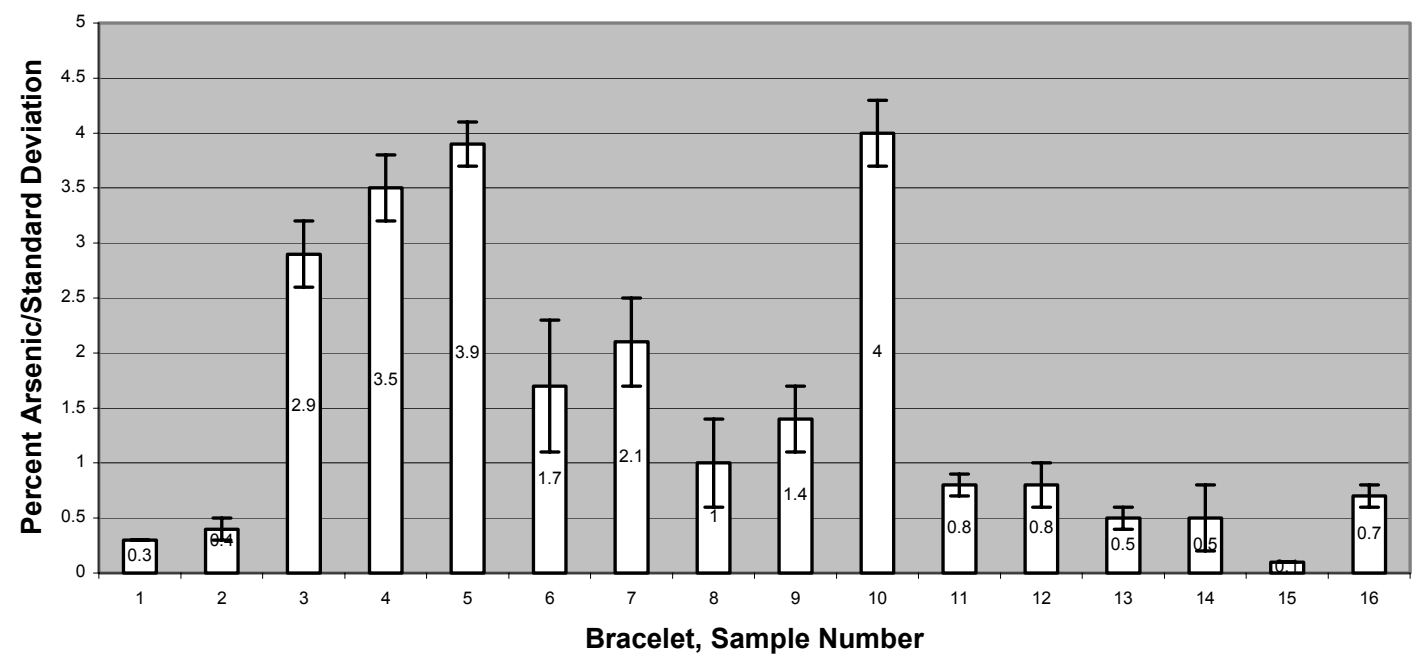

The bracelets were also examined for antimony and arsenic because of the occurrence of these two elements in conjunction with both lead and tin ores throughout the world, as is evidenced by their proximity on the periodic table [6]. While arsenic was present in all the bracelets, it was routinely a trace element, only rising above $2 \%$ in five samples, and only reaching $3-4 \%$ in three samples. The amount of antimony present in the samples varied widely however, from under 0.3 $2.1 \%$ in bracelets $3-10$, to a $7-13 \%$ range in bracelets 1 and 2, and $11-14$. This range of antimony values does correspond closely though with the designation of a bracelet as either being an atoni, or an onoudu. The atoni samples are all high antimony pieces, while the onoudu are low. Bracelets 15 and 16 showed almost no antimony.

\section{ELEMENTAL COMPOSITION, THE KING MANILLA}

King manilas are significantly rarer than the small manilas, which makes most of them the provenance of museums or wealthy collectors today. Consequently, this research is only able to compare one king with a larger number of small manillas. Despite this sample size, it appears that the king manilla was manufactured in a different manner or by a different business concern than the other samples, because it has an average copper composition in excess of $95 \%$.

Whereas the small manillas were each analyzed at six points, as indicated above, the king manilla was $x$-rayed at 11 points on each side. The eleven points were then averaged, producing the following picture of its elemental composition: 


$\begin{array}{lc}\text { Element } & \text { Percent Composition } \\ \mathrm{Cu} & 95.8 \\ \mathrm{~Pb} & 0.91 \\ \mathrm{Zn} & 0.11 \\ \mathrm{Sn} & 0.04 \\ \mathrm{As} & 1.06 \\ \mathrm{Sb} & 0.94\end{array}$

This is essentially a copper object, admittedly with trace elements present, but with a much purer composition than those manillas of known European manufacture. While lead and arsenic are present at close to $1 \%$ each, both of these could have been residual impurities from a copper ore.

\section{CONCLUSIONS}

Clearly, the chemical composition of African trade manillas varies widely from published, historical accounts. In a number of cases, lead was far from a minor component in these trade items. While lead has been added to metal alloys in different cultures at different times throughout history [7-9], the claim can be made that a small amount of lead lowers the melting point of many alloys, including copper-based alloys, making them easier to work. The addition of so much lead into these bracelets though, may very well have been an attempt to maximize trading company profits in the bulk production of manillas.

Antimony may serve as a chemical fingerprint in these samples to help determine the location of ore sources. Further study, and research through the historical archives of European trading companies may have to be undertaken to determine if antimony content can be directly correlated to either copper mining, or lead mining.

The king manilla definitely appears to have been produced in some location other than that of the smaller, trading manillas. References indicate that king manillas were cast in Africa, which is lent credence by these results.

\section{ACKNOWLEDGEMENTS}

The authors wish to thank the United States National Science Foundation, grant number 98-51311 as well as the University of Detroit Mercy for the purchase of the energy dispersive X-ray fluorescence spectrometer, and the American Chemical Society's Project SEED for Vincent Iduma's involvement in this research.

\section{APPENDIX}

Photographs of manillas 1-16 (labeled) and of the King manilla (unlabeled).
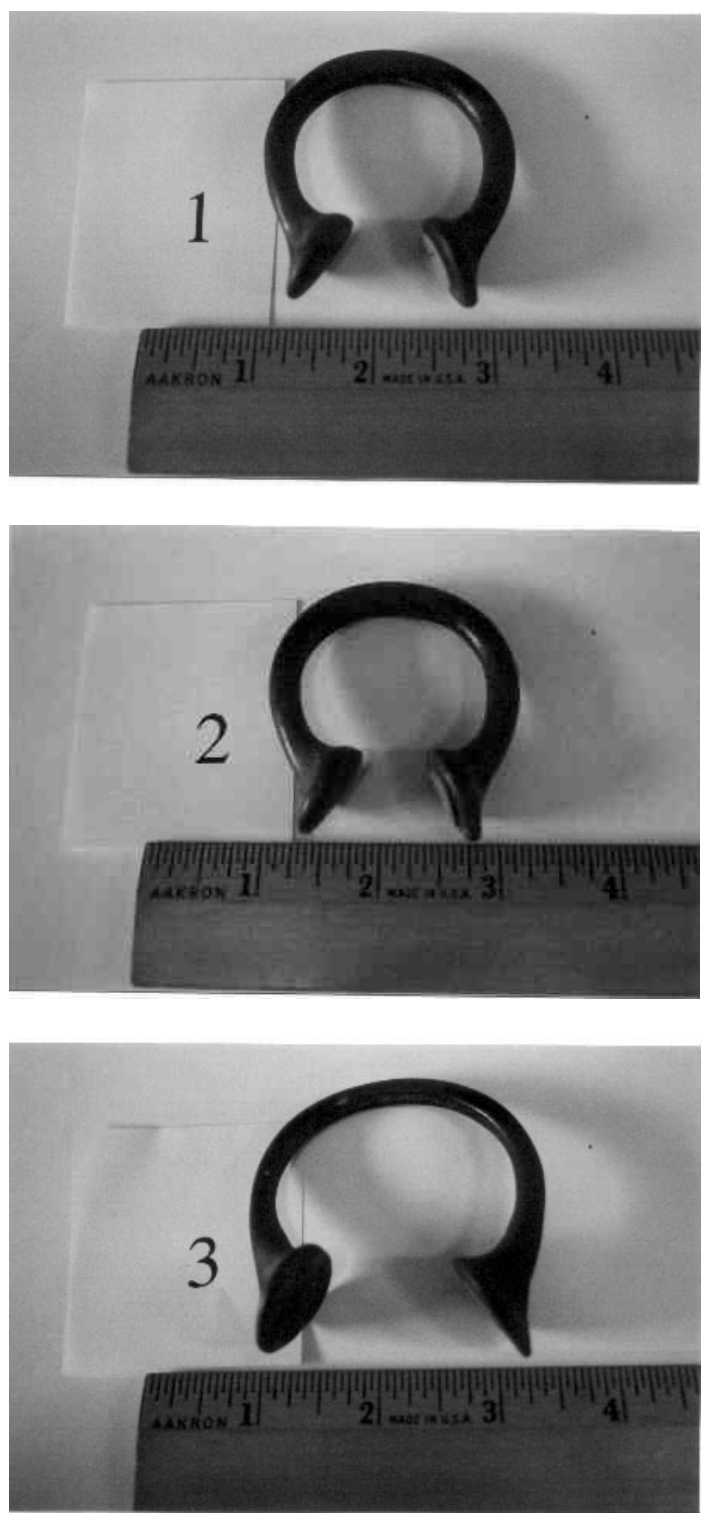

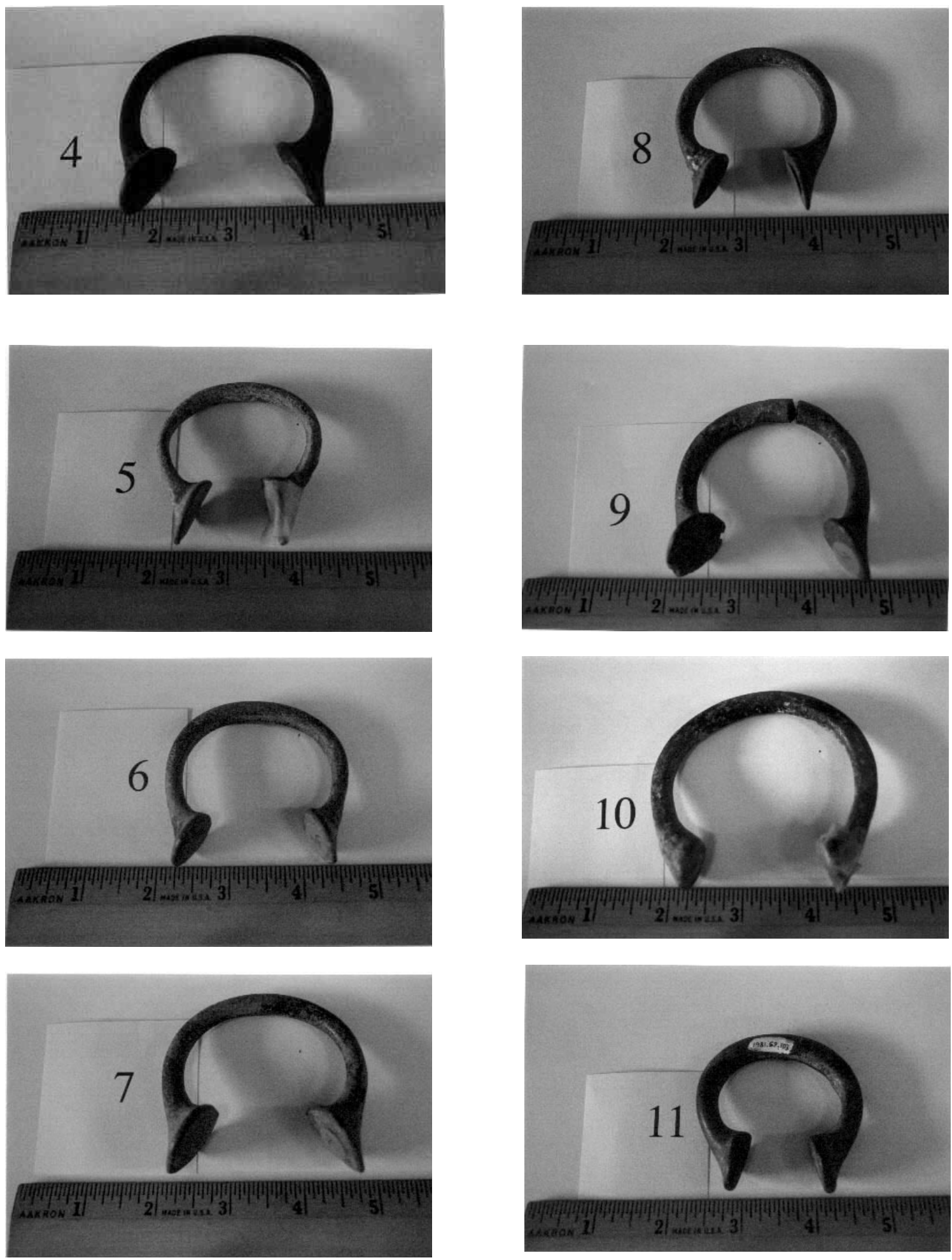

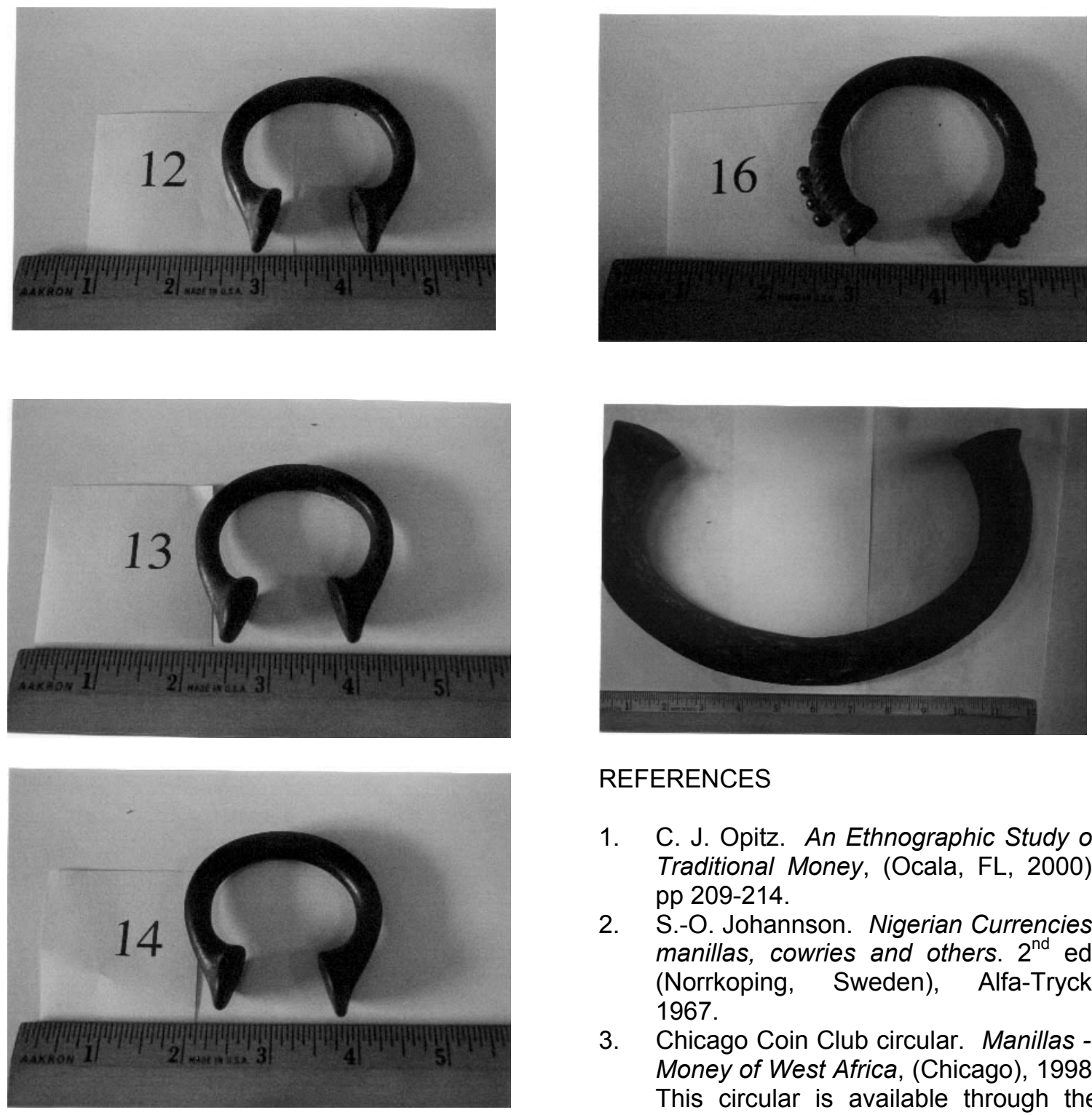

\section{REFERENCES}

1. C. J. Opitz. An Ethnographic Study of Traditional Money, (Ocala, FL, 2000), pp 209-214.

2. S.-O. Johannson. Nigerian Currencies, manillas, cowries and others. $2^{\text {nd }}$ ed. (Norrkoping, Sweden), Alfa-Tryck, 1967.

3. Chicago Coin Club circular. Manillas -Money of West Africa, (Chicago), 1998. This circular is available through the Chicago Coin Club, P.O. Box 2301, Chicago, IL 60690

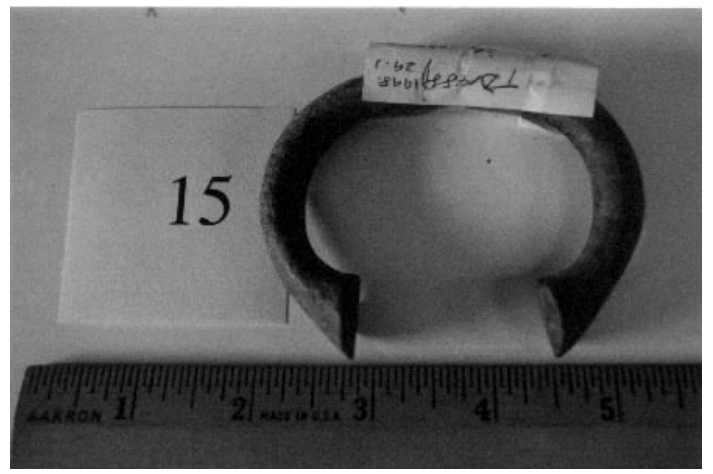

4. R.F.A. Grey. "Manillas," Nigerian Field, XVI, (1951), pp 52-56.

5. G.F. Carter, ed., Archaeological Chemistry II, (American Chemical Society, Washington, DC, 1978), pp 278-292.

6. N.N. Greenwood and A. Earnshaw, Chemistry of the Elements, Pergamon Press, Oxford, England, 1984, pp 638640. 
7. G.F. Carter, ed., Archaeological Chemistry II, (American Chemical Society, Washington, DC, 1978), pp 293-334.

8. J.B. Lambert, ed., Archaeological Chemistry III, (American Chemical Society, Washington DC, 1984), pp 311-329.

9. R.O. Allen, ed., Archaeological Chemistry IV, (American Chemical Society, Washington, DC, 1989), pp 159198. 
